\title{
EUROPE'S INITIAL EXPERIENCE WITH PANDEMIC (H1N1) 2009 - MITIGATION AND DELAYING POLICIES AND PRACTICES
}

\author{
A Nicoll (Angus.Nicoll@ecdc.europa.eu) ${ }^{1}$, D Coulombier ${ }^{1}$ \\ 1. European Centre for Disease Prevention and Control, Stockholm, Sweden
}

Europe has experienced more than two months of the first transmissions and outbreak of the 2009 pandemic of $A(H 1 N 1) v$. This article summarises some of the experience to date and looks towards the expected autumn increases of influenza activity that will affect every country. To date the distribution of transmission has been highly heterogenous between and within countries, with one country the United Kingdom (UK) experiencing the most cases and the highest transmission rates. Most infections are mild but there are steadily increasing numbers of people needing hospital care and more deaths are being reported. An initial difference in practice between Europe and North America was over case-finding and treatment with some authorities in Europe using active casefinding, contact tracing and treatment/prophylaxis with antivirals to try and delay transmission. This article details the history of this practice in the past two months and explains how and why countries are moving to mitigation, especially treating with antivirals those at higher risk of experiencing severe disease.

\section{The current situation in the United States and Europe}

In the three months since its first recognition the pandemic strain of influenza $A(H 1 N 1) v$ virus has spread to all six continents [1]. So many people are being infected that the World Health Organization (WHO) considers counting cases of little value in the more affected countries and hence it has advised to stop testing and reporting individual cases and to move on to other surveillance strategies [2]. In the temperate areas of the southern hemisphere, where it is winter, the first pandemic wave is in progress. In the northern hemisphere most countries are in the initiation phase (Figure).

The United States Centers for Disease Control and Prevention (CDC) broadly estimates that at least a million people have been infected with the pandemic virus in the United States, a large figure, but representing only $0.3 \%$ of the US population compared to the $20-30 \%$ that is anticipated to be affected in the first wave in the winter season [3]. The picture is also heterogeneous geographically as is often the case with both seasonal and pandemic influenza. Up to $7 \%$ of the population may have been infected in New York city in May, while other places are reporting only a few infections $[4,5]$. CDC expects the virus to keep spreading in the US through the summer and then transmission to accelerate in the autumn [6].

In the European Union all countries have now reported cases and the picture is even more heterogeneous than in the US [1]. Two countries, Spain and the UK account for more than four fifths of the reported cases and France and Germany have recently also reported significant numbers $[1,7]$. Hospitalisations and deaths are mounting up and the most affected country (UK) has revised its planning assumptions for a major first wave in the light of its particular experience (Table 1) [8].

Reported case numbers will become increasingly meaningless as countries abandon trying to test all cases and stop being able to count cases. However the initial analyses give important information. Initially case reports in Europe were dominated by imported (travelrelated) cases [9]. These now represent ever decreasing proportions. In the latest cumulative analysis they accounted for only $13 \%$ $(1,946$ of 14,146$)$ reported cases and the countries that have reported substantial numbers have all observed a strong trend of predominating domestically-acquired infections [7].

The most affected country is the UK and its experience gives useful indications of what is to come. Again the picture is one of heterogeneity with some parts of the UK experiencing intense transmission indicating the start of an acceleration phase with numbers of primary care consultations several times higher that

\section{F I G U R E}

Idealised national curve for planning, Europe 2009 (reality is never so smooth and simple)

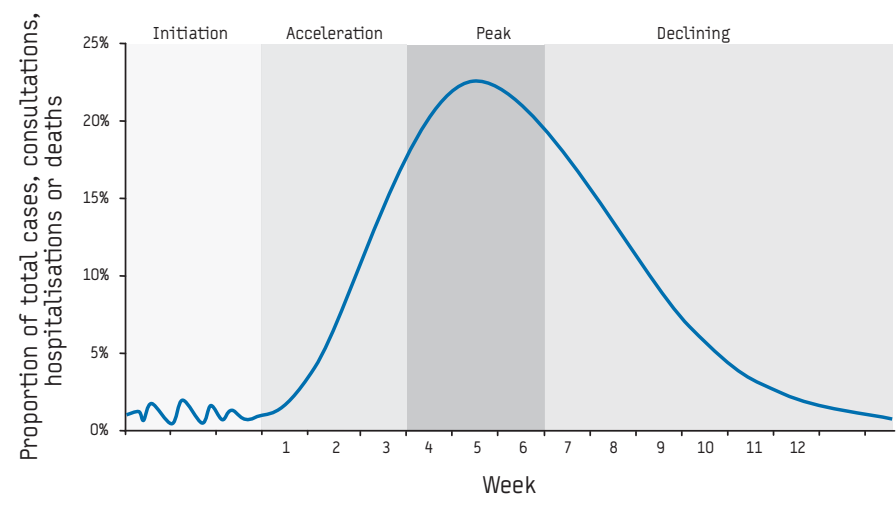

Single-wave profile showing the proportion of new clinical cases, consultations, hospitalisations or deaths by week. Based on influenza pandemic in London in 1918, second wave. 
those experienced at the peak of last winter (when seasonal influenza was the worst in some years) [10]. However other parts are relatively unaffected [10]. The most recent numbers (as of 23 July) are available at the website of the Health Protection Agency: http://www.hpa.org.uk/webw/HPAweb\&HPAwebStandard/HPAweb_ $\mathrm{C} / 1247816558780 ? \mathrm{p}=1231252394302$

Overall the modelled estimated rate of new infections for the week of 23 July of $0.2 \%$ (100,000 in the week) in the UK is still someway down the acceleration phase but according to the UK's planning assumptions it might be expected to peak at about $6.5 \%$ or around 800,000 clinical infections per week (Table 1) [8].

\section{Severity of the disease and risk groups}

It remains the case that most people who are infected in Europe experience a mild illness that does not require treatment. However this in itself is making surveillance more difficult since most people will not need to seek medical attention when infected [11]. For example in a New York city survey very few of the people reporting illness thought it was sufficiently serious to seek medical care (I Weisfuse, personal communication). Certainly many cases are also not coming to the attention of surveillance in Europe.

\section{T A B L E 1}

United Kingdom revised planning assumptions for the pandemic - first wave A(H1N1) 2009

\begin{tabular}{|l|l|}
\hline Clinical attack rate & $30 \%$ \\
\hline Peak clinical attack rate & $\begin{array}{l}6.5 \% \text { (local planning assumption } 4.5 \% \\
\text { to } 8 \% \text { ) per week }\end{array}$ \\
\hline Complication rate & $15 \%$ of clinical cases \\
\hline Hospitalisation rate & $2 \%$ of clinical cases \\
\hline Case fatality rate & $0.1-0.35 \%$ of clinical cases \\
\hline Peak absence rate & $12 \%$ of workforce \\
\hline
\end{tabular}

Source: United Kingdom Department of Health:

http://www.dh.gov.uk/en/Publicationsandstatistics/publications/ PublicationsPolicyAndGuidance/DH_102892

T A B L E 2

Risk groups for the pandemic (H1N1) 2009

The following groups are considered more at risk of experiencing severe disease than the general population should they become infected with the pandemic A(H1N1)v virus 2009:

People with chronic conditions in the following categories:

- chronic respiratory diseases:

- chronic cardiovascular diseases (though not isolated mild hypertension):

chronic metabolic disorders (notably diabetes);

chronic renal and hepatic diseases;

persons with deficient immunity (congenital or acquired); chronic neurological or neuromuscular conditions; and any other condition that impairs a person's immunity or prejudices their respiratory (breathing) function, including severe or morbid obesity.

Note: These categories will be subject to amendment and development as more data become available. These are very similar underlying conditions that serve as risk factors for seasonal influenza. What is especially that serve as risk factors for seasonal influenza. What is especially
different from seasonal influenza is that the older age groups (over the different from seasonal influenza is that the older age groups (over the
age of 60 years) without underlying conditions are relatively unaffected age of 60 years) without by the pandemic strain.

\section{Pregnant women}

Young children (especially those under two years)
Crucial information is being published on the higher risk groups (those who are more likely to experience severe disease). The conclusions are still preliminary but the initial data from North America and Europe on who is affected by severe symptoms indicate risk groups similar to those for seasonal influenza, though with some important differences, notably the relative absence of cases in older people [12] (Table 2).

\section{Expectations for the autumn in Europe}

The European Centre for Disease Prevention and Control (ECDC) expects that in autumn European countries will experience a major first wave well beyond anything that has been experienced to date in this pandemic (Figure) [11]. However it is not possible to predict exactly what percentage of the population will be infected in the autumn wave and when it will come for individual countries. It is unlikely to occur at once and there will be heterogeneity within countries. Even if the experience of the UK is that the first acceleration phase of the pandemic truncates in the summer (perhaps as schools close), ECDC considers it important to prepare for an earlier start in autumn than the time when seasonal influenza usually takes off. Based on the initial surveillance results the UK has revised its planning assumptions for up to $30 \%$ of the population to be affected in the first wave [8] (Note: It is important here to distinguish between planning assumptions and predictions. Planning assumptions represent the reasonable worst case scenarion for a first major pandemic wave).

Hence Europe should be prepared to experience a very large number of cases in the coming months with inevitable strain on the health services because of a proportion of cases requiring primary or secondary care $[11,13-15]$ (Table 1). A new approach to surveillance, building on what is already there will be needed and that is being developed by ECDC with Member States and WHO.

\section{Initial differences in practises between North America and \\ Europe}

An area of differing practice or even policy between countries has been how to manage the initial cases and transmissions of influenza $\mathrm{A}(\mathrm{H} 1 \mathrm{~N} 1) \mathrm{v}$ virus. In North America the approach from the start was of mitigation, essentially following WHO's early advice (Table 3) [16]. This includes applying standard guidance on the management of influenza cases and outbreaks similar to those for seasonal influenza, not treating the majority of cases who experience a mild self-limiting illness but offering antivirals to those who are considered at higher risk of experiencing severe disease $[17,18]$. Prophylaxis is being reserved for these groups when they are thought to have been exposed.

In Europe the initial approach was different from North America with some countries starting by attempting containment (trying to stop influenza spread beyond initial outbreaks) with energetic case-finding, treatment, contact-tracing and chemoprophylaxis of contacts (Table 3). Cases were isolated in hospital and quarantine was practised. A country that typified this approach was the UK which practised active finding and treatment of cases and contacts in schools and families, although not isolation in hospital or quarantine [19]. Though the word containment was used this was better described as delaying (Table 3 ). Despite great efforts in May and June daily reports of new laboratory confirmed cases rose to over 500 a day in late June. Hence, the UK found it difficult to sustain the intensive case-finding and contact-tracing strategy and on 2 July announced it was moving to a mitigation strategy which it called a treatment approach [20]. The principle is to make 
antivirals available for all, but focusing especially on the early treatment of those in risk groups and to limit the use of prophylaxis to protect those at higher risk of severe disease [20]. Some other European countries have also treated all cases and contacts [21] but as their numbers of detected cases are small they were initially able to manage this more readily.

The question therefore was which practise should all European countries follow when they are inevitably affected, either over the summer or sometime in the autumn? Following a request from EU member states for guidance, in June ECDC published the arguments for and against these approaches, which this article will now summarise $[22,23]$.

\section{WHO's position on containment}

When announcing pandemic phase 4 , WHO indicated that the epidemic had already started to spread beyond a level justifying attempts at containment and a mitigation approach was recommended [16]. Two days later, on 29 April, WHO escalated to phase 5 and then on 11 June to phase 6 . According to WHO guidance, under phases 5 and 6 , measures differ between affected and not yet affected countries but containment attempts are no longer recommended, the guidance advises member states to implement a mitigation strategy, including considering measures for reducing the spread of infection $[16,24]$. This includes applying standard guidance on the management of influenza cases and outbreaks similar to those for seasonal influenza (Table 3 ). This

T A B L E

Mitigation, containment and delaying - the definitions

Mitigation is a collective term recommended by WHO for actions in affected countries in phases 5 and 6 of pandemic alert, essentially reducing the impact of a pandemic.

In the health sector, the aims of mitigation include:

- reducing the overall number of people affected

reducing transmission;

ensuring healthcare for those who may be infected;

ensuring healthcare for those who may be

maximising care for those with dise

more general interventions.

\section{Containment}

Containment means preventing spread of a infection in a defined areas or areas by:

- case-finding: detecting imported infections and first generation case-finding: detectin

- taking actions to prevent their turning into chains of

transmission and outbreaks, notably through vigorous contact transmission and outbreaks, notably through vigor

The objective is to stop as many transmissions as possible and eventually the outbreak 'burns out'.

The term 'containment' is not recommended in this context by WHO or ECDC as it raises expectations that a pandemic virus can be contained ECDC as it raises expectations that a pandemic virus can be contain

2009 virus because, when it was discovered, transmission was already 2009 virus because, when it was

Delaying is a less complete form of containment where the aim is not to contain the pandemic but rather to simply slow down transmission.

\section{Differences}

It is important to note that many of the actions and messages being undertaken or promulgated are the same for delaying and mitigation strategies.

What is different between the two is that in delaying there is special emphasis put on:

1. Vigorous case-finding and tracing of contact-persons and giving antivirals or alerting them to watch for symptoms;

2. Putting contact-persons or even all travellers from areas with community transmission under quarantine. entails not treating the majority of cases who experience a mild selflimiting illness but offering antivirals to those who are considered at higher risk of experiencing severe disease [16-18]. Neither ECDC nor WHO recommend the use of the word 'containment' for influenza outside of the theoretical context of place and time where a pandemic strain first emerges somewhere in the world [25]. Previous modelling work has suggested that containment will be both impractical and unsuccessful once there is extensive community transmission and certainly once the pandemic has entered its acceleration phase [26]. Apart from some very isolated settings, history dictates that European communities will not be able to contain the pandemic strain or isolate themselves from it [27].

\section{The experience with delaying and containment}

The 'delaying' strategy was certainly legitimate to attempt, especially in the EU where the initiation phase started at the very end of the seasonal influenza period when influenza transmission would be expected to be low. The delaying strategy is therefore appealing when a pandemic starts in the spring or early summer. The rationale is that an aggressive approach could decrease the effective reproduction number $(R)$ and delay the inevitable acceleration of the pandemic until autumn allowing more time for preparations and for vaccines to be developed and licensed. Besides, identifying the first cases and documenting their clinical presentation has proven to be important at the early stages of a pandemic to gather information needed for the early assessment to steer the strategy for response $[14,15,28)$.

\section{Operational aspects}

The main issues around the debate on mitigation versus delaying are operational and concern the opportunity costs of aggressive case-finding, contact tracing and management (Table 3). The question is whether there are staff available who can deliver the necessary response seven days a week and what else cannot be done because the human and other resources are fully engaged on case-finding, contact-tracing, testing and treating. In the UK delivering the delaying strategy was initially possible because the Health Protection Agency and Health Protection Scotland led the work and combined effectively with local public health and primary care staff to focus massive effort on the initially affected communities. At the same time central authorities concentrated on making final preparations especially readying the health services for the autumn wave. Even so the intense work involving many schools and families was unsustainable. This has demonstrated that where there is active influenza transmission the strain on the work-force from attempting delaying is considerable. Probably only countries with national public health workforces who can be moved around the country could implement such a policy at the population level during initiation. Once into the acceleration phase in the autumn the task will be impossible in any country given what is known now about the effective reproductive number [29]. Australia and New Zealand are unusual in having formal containment phases in their pandemic plans. Their current experience is telling for what Europe could expect in the autumn. Both these countries moved through and beyond containment rapidly into mitigation $[30,31]$.

\section{Communication challenges}

Besides burden on staff there are major communication challenges from an initial delaying approach. These arise from starting on a delaying tactic and treating everyone with what may seem a very mild disease, plus their contacts. Then having to move back to mitigation with only offering antivirals to those in the risk 
groups $[8,10]$. Explaining this to professionals and the public may not be easy. It is also not clear how it is possible to get patients, especially children to take antivirals and complete course when they are only experiencing mild disease or are contacts of cases [32].

\section{Differences between mitigation and containment}

It should be appreciated that looked at overall mitigation and delaying strategies have a lot in common. They only differ in the emphasis in delaying on finding as many infectious cases as possible and treating them and their contacts (Table 3) However that difference is very important as the UK found the work is very demanding on human resources in the field and in the laboratory. This is especially so with using antivirals because of the evidence that to be effective treatment has to be given early, within 48 hours of symptoms starting [33,34].

\section{Exit strategies}

If a country decides to adopt delaying it needs to have a very clear exit strategy and triggers for giving up. ECDC does not recommend delaying but if a country does adopt the policy then it could consider the ECDC criteria for being 'affected' as the sign it is time to change to mitigation in all parts of the country [35]. Once policy makers adopt delaying or containment as a formal policy rather than an operational practice it can be especially difficult to change policy in a timely manner and so it is best to keep decisions at the technical level. An additional factor influencing the choice of strategy is that if a number of countries in Europe started on delaying or containment then others might have felt they had to follow. Unlike in the United States and Canada there are no cross-European agreed recommendations on the use of antivirals (although there is an ECDC guidance) [34]. It is therefore difficult to explain why delaying is being done in one country and not in others and this problem will arise again (i.e. in the autumn). Some solution was offered by meetings that took place in early July where experts met to discuss this topic and advised ministers at an informal EU Health Council to allow a degree of coordination. There was also broad agreement based on the UK example that mitigation should be adopted either in the initiation phase or when acceleration starts (Figure) in individual countries [36,37].

\section{Has delaying been effective?}

Have attempts at case-finding, contact tracing and treatment of all cases and contacts been effective in Europe so far? The

TA B L E 4

Infectiousness of some communicable diseases

\begin{tabular}{|l|l|l|}
\hline Infection & $\begin{array}{l}\text { Effective (R) or basic } \\
\text { reproductive rate (Ro) }\end{array}$ & Notes \\
\hline Seasonal influenza & R around $1.1-1.2$ & $\begin{array}{l}\text { Higher in crowded } \\
\text { communities }\end{array}$ \\
\hline Pandemic influenzas & $R=1.5$ to 2.5 & $\begin{array}{l}\text { Higher in crowded } \\
\text { communities }\end{array}$ \\
\hline Pandemic (H1N1) 2009 & $R=1.5$ to 2 & $\begin{array}{l}\text { Presumed higher in } \\
\text { crowded communities }\end{array}$ \\
\hline Measles & Ro $>10$ & \\
\hline Mumps & Ro 4 to 7 & \\
\hline
\end{tabular}

$\mathrm{R}=$ effective reproductive rate $=$ the average actual number of people

that are observed to be infected by one infected person
Ro $=$ basic reproductive rate $=a$ theoretical concept of the average Ro $=$ basic reproductive rate $=$ a theoretical concept of the average
number of people that one person infects in a wholely susceptible number of answer depends on whether effectiveness is considered at the individual or population level. For those infected and treated within 24 to 48 hours the answer is almost certainly 'yes'. Trials of both the neuraminidase inhibitors, oseltamivir and zanamivir against seasonal influenza have shown benefit in otherwise healthy adults $[33,34]$ although it must be appreciated that antivirals are not 'magic bullets'. Even if given in time they only shorten the illness by one or two days and do not stop a person being infectious $[33,34]$. There may be more benefit when antivirals are given to those developing severe illness [34]. There are no such data for the pandemic strain as yet but since only a handful of viruses have shown genetic markers of resistance to either drug (they do have markers of resistance to the adamantenes) a reasonable default assumption is that they should be effective for treatment of infected individual $[34,40]$ The arguments around prophylaxis are more complicated. Certainly many episodes of illnesses will have been prevented but we do not know how successful prophylaxis is in preventing actual infection rather than just preventing the onset of symptoms. A sophisticated view, not supported by ECDC, recalls the accounts of the 1918-19 pandemic, which was also the last A(H1N1)-based pandemic. Then a lower pathogenicity wave in the spring in Europe was followed by a much higher pathogenicity wave in the autumn [41]. So the logic goes it may be better to be infected now by this mild $A(H 1 N 1) v$ virus rather than later by one causing more severe disease.

At a population level it is harder to determine the success of the delaying tactic. Delaying can appear to work by chance alone. Pandemics of influenza, like seasonal influenza each autumn, take an uncertain time to move from initiation to acceleration (contrary to popular belief influenza is only 'infectious' not 'highly infectious' (Table 4)) Considering the United States since April the heterogeneity of transmission has been striking [5]. If relatively pandemic-spared cities like those on the West Coast had attempted delaying they might now be congratulating themselves while cities like Chicago and New York would be wondering what they did wrong. It is highly possible that the efforts made by the UK and other European countries delayed the progression of transmission in May and June. Indeed given the scale of the effort in the UK it seems hard to imagine there has not been some benefit but a final verdict on how much delaying was achieved will have to await the results of considered evaluations which will take some time.

\section{What to do?}

In conclusion, what should a European country do when confronted by first cases? It can be difficult when there are only a handful of cases to offer no treatment except to individuals in risk groups. But that may be what national policies dictate, what WHO recommends and what is being done in North America [16-18]. It would also seem to be in line with the ECDC documents [22,23].

When confronted with more cases countries should consider whether to attempt delaying at all, what the advantages are of any time it might buy and the opportunity costs from what else will not be done as a consequence. The conclusion of the Swedish Presidency meeting was that countries should move to mitigation $[36,37]$, and at least two more countries report having taken this decision $[38,39]$.

However that does not mean that the first cases and transmissions in a country do not deserve special attention. There are very legitimate reasons for undertaking enhanced surveillance and working closely with those first affected to determine some of the 
known unknowns of the pandemic - for example: what proportions of people in a family are affected, are most older people really immune, how long are people infectious, do those who choose to take antivirals stop excreting virus and do they develop immunity [14,15,40-45] A number of countries are undertaking such work in Europe and ECDC and WHO are working with them to ensure the rapid sharing of protocols and data.

\section{References}

1. European Centre for Disease Prevention and Control. ECDC Situation Report. 23 July 2009. Available from: http://www.ecdc.europa.eu/en/files/pdf/Health_ topics/Situation_Report_090722_1700hrs.pdf

2. World Health Organization. WHO Pandemic (H1N1) 2009 briefing note 3. Changes in reporting requirements for pandemic (H1N1) 2009 virus infection. 16 July 2009. Available from: http://www.who.int/csr/disease/swineflu/notes/h1n1 surveillance_20090710/en/index.html

3. Centers for Disease Control and Prevention (CDC). CDC mediabriefing on investigation of human cases of novel influenza A (H1N1). 26 June 2009. Available from: http://www.cdc.gov/media/transcripts/2009/t090626.htm

4. New York City Department of Health and Mental Hygiene, Results of Survey. 10 June 2009. Available from: http://www.nyc.gov/html/doh/html/pr2009/ pr041-09.shtml

5. Centers for Disease Control and Prevention (CDC). CDC Flu View 2008-2009. Influenza Season Week 27 ending July 11, 2009. Available from: http://www. cdc.gov/flu/weekly/

6. Centers for Disease Control and Prevention (CDC). CDC mediabriefing on investigation of human cases of novel influenza A (H1N1). 18 June 2009. Available from: http://www.cdc.gov/media/transcripts/2009/t090618.htm

7. European Centre for Disease Prevention and Control. ECDC Surveillance Report. Analysis of influenza A(H1N1)v individual case reports in EU and EEA countries. Update 17 July 2009. Available from: http://www.ecdc.europa.eu/en/files/pdf/ Health_topics/090717_Influenza_A(H1N1)_Analysis_of_individual_data_EU_ EEA-EFTA.pdf

8. UK Department of Health and Cabinet Office. Swine flu: UK planning assumptions. 16 July 2009. Available from: http://www.dh.gov.uk/en/ Publicationsandstatistics/Publications/PublicationsPolicyAndGuidance/ DH_102892

9. European Centre for Disease Prevention and Control. ECDC working group on influenza A(H1N1)v. Preliminary analysis of influenza A(H1N1)v individual and aggregated case reports from EU and EFTA countries. Available from: http:/ www.eurosurveillance.org/ViewArticle.aspx?ArticleId=19238Eurosurveillance

10. Health Protection Agency (HPA). Weekly pandemic flu update. 23 July 2009. Available from: http://www.hpa.org.uk/webw/HPAweb\&HPAwebStandard/HPAwe b_C/1247816558780?p=1231252394302

11. European Centre for Disease Prevention and Control. Jakab Z. Pandemic 2009-10. ECDC's future look and risk assessment. Briefing to the Swedish Presidency Informal Council, Jonkoping, Sweden, 6 July 2009. Speaking notes and presentation. Available from: http://www.ecdc.europa.eu/en/files/Ppt/ ZJ_Pandemic_2009_2010_Future_Look_and_Risk_Assessment.pdf http://www. ecdc.europa.eu/en/files/Ppt/ZJ_Presentation_on_the_2009_2010_Pandemics. ppt

12. Centers for Disease Control and Prevention (CDC). Finelli L. Influenza Surveillance. ACIP Meeting 24-25 June 2009. Available from: http://www.cdc. gov/vaccines/recs/ACIP/downloads/mtg-slides-jun09/15-2-inf.pdf

13. European Centre for Disease Prevention and Control. Surveillance and studies in a pandemic. Background papers for working groups. Stockholm 14-15 2009. Available from: http://www.ecdc.europa.eu/en/files/pdf/Health_topics/0907_ Surveillance_and_Studies_in_a_Pandemic_Background_Paper.pdf

14. European Centre for Disease Prevention and Control. Surveillance and studies in a pandemic. Technical report. June 2009. Available from: http://www. ecdc.europa.eu/en/files/pdf/Health_topics/Surveillance_and_studies_in_a_ pandemic_in_Europe.pdf

15. World Health Organization. Global surveillance during an influenza pandemic. Geneva, 2009. Available from: http://www.who.int/csr/resources/publications/ swineflu/surveillance/en/index.html

16. World Health Organization. Press briefing Dr Keiji Fukuda. Geneva 2009. Available from: http://www.who.int/mediacentre/multimedia/swineflu_ presstranscript_2009_04_26.pdf

17. Centers for Disease Control and Prevention (CDC). Interim guidance on antiviral recommendations for patients with novel influenza $A(H 1 N 1)$ virus infection and their close contacts. 6 May 2009. Available from: http://www.cdc.gov/ h1n1flu/recommendations.htm

18. Public Health Agency of Canada. Use of antivirals to treat H1N1 flu virus (human swine flu). 1 May 2009. Available from: http://www.phac-aspc.gc.ca/ alert-alerte/swine-porcine/antiviral-antiviraux05-01-eng.php
19. Department of Health, United Kingdom. Statement. 29 May 2009. Available from: http://www.dh.gov.uk/en/News/Recentstories/DH_099966

20. Department of Health, United Kingdom. $A(H 1 N 1)$ swine influenza: from containment to treatment. Available from: http://www.dh.gov.uk/en/ Publichealth/Flu/Swineflu/InformationandGuidance/index.htm

21. Anonymous, Robert Koch Institute. Modifiikationsmoglichkeiten des Strategie zur Bekampfung / Eindammung der Neuen Influenza A/H1N1 in Deutschland in Abhangigkeit von der Entwicklung der Ausbreitung un der Schwere der Erkrankungen. Available from: http://www.rki.de/cln_091/nn_196322/DE/ Content/Infekt/EpidBull/Archiv/2009/27__09,templateId=raw,property=public ationFile.pdf/27_09.pdf

22. European Centre for Disease Prevention and Control. Interim guidance. Mitigation and delaying (or 'containment') strategies as the new influenza A(H1N1) virus comes into Europe. 6 June 2009. Available from: http://ecdc. europa.eu/en/files/pdf/Health_topics/090606_Delaying_vs_Mitigation_ Interim_ECDC_Guidance.pdf

23. European Centre for Disease Prevention and Control. Health Information How to communicate response strategiesto influenza A(H1N1)v:Mitigation versus delaying. 15 June 2009. Available from: http://ecdc.europa.eu/en/ files/pdf/Health_topics/Key_messages_on_influenza_H1N1_Mitigation_vs_ delaying_150609.pdf

24. World Health Organization. Pandemic influenza preparedness and response 2009. Recommended Actions in Phase 5 \& 6. Available from: http://www.who. int/csr/disease/influenza/extract_PIPGuidance09_phase5_6.pdf

25. World Health Organization. WHO Interim Protocol: Rapid operations to contain the initial emergence of pandemic influenza. Geneva 2007. Available from: http://www.who.int/csr/disease/avian_influenza/guidelines/draftprotocol/en/ index.html

26. Ferguson NM, Cummings DA, Fraser C, Cajka JC, Cooley PC, Burke DS. Strategies for mitigating an influenza pandemic. Nature. 2006;442(7101):448-52.

27. Markel H, Stern AM, Navarro JA, Michalsen JR, Monto AS, DiGiovanni C. Nonpharmaceutical influenza mitigation strategies, US communities, 19181920 pandemic. Emerg Infect Dis. 2006;12(12):1961-1964.

28. Hahné S, Donker T, Meijer A, Timen A, van Steenbergen J, Osterhaus A, et al. Epidemiology and control of influenza $A(\mathrm{H} 1 \mathrm{~N} 1) v$ in the Netherlands: the first 115 cases. Euro Surveill. 2009;14(27):pii=19267. Available from: http://www. eurosurveillance.org/ViewArticle.aspx?ArticleId =19267

29. Fraser C, Donnelly CA, Cauchemez S, Hanage WP, Van Kerkhove MD, Hollingsworth TD, et al. Pandemic potential of a strain of influenza A (H1N1): early findings. Science. 2009 Jun;324(5934):1557-61.

30. Jennings LC, Influenza A(H1N1)09: New Zealand's response to the pandemic threat. New Zealand Med J. 2009;122;11-16.

31. Australian Government Department of Health and Aging. New Pandemic Phase - Protect. 17 June 2009. Available from: http://www.healthemergency.gov.au/ internet/healthemergency/publishing.nsf/Content/news-170609

32. Kitching A, Roche A, Balasegaram S, Heathcock R, Maguire H. Oseltamivir adherence and side effects among children in three London schools affected by influenza A(H1N1)v, May 2009 - an internet-based cross-sectional survey. Euro Surveill. 2009 [forthcoming]

33. Halloran ME, Haydn FG, Yang Y, Longini IM, Monto AS. Antiviral effects on influenza transmission and pathogenicity: observations from household based trials. Am J Epidemiol. 2007;165(2):212-21.

34. European Centre for Disease Prevention and Control. ECDC Interim Guidance. Public health use of influenza antivirals during influenza pandemics. July 2009. Available from: http://www.ecdc.europa.eu/en/files/pdf/Publications/0907_GUI_ Public_Health_use_of_Influenza_Antivirals_during_Influenza_Pandemic.pdf

35. European Centre for Disease Prevention and Control. ECDC Technical Report. Influenza A(H1N1)v infection - Terminology for affected areas. 3 July 2009. Available from: http://www.ecdc.europa.eu/en/files/pdf/Health_topics/0907_ Influenza_AH1N1v_Terminology_for_Affected_Areas.pdf

36. Swedish Presidency of the European Union. Summary from the Presidency meeting: Pandemic influenza preparedness - lessons learned and nex steps; Jönköping 2-3 July. 5 July 2009. Available from: http://www.se2009. eu/polopoly_fs/1.8266!menu/standard/file/Summary_draft_J\%C3\%B6nk\%C3\%B6 ping_090705_final.pdf

37. Swedish Presidency Press release: Important steps towards an EU strategy for pandemic preparedness. Jonkoping, Sweden. 16 July 2009. Available from: http://www.se2009.eu/en/meetings_news/2009/7/6/press_release_important steps_towards_an_eu_strategy_for_pandemic_preparedness 38. Influenza $A(\mathrm{H} 1 \mathrm{~N} 1) \mathrm{v}$ investigation teams. Modified surveillance of influenza $A(\mathrm{H} 1 \mathrm{N1})$ v virus infections in France. Euro Surveill. 2009;14(29):pii=19276. Available from: http://www.eurosurveillance.org/ViewArticle.aspx?ArticleId=19276

39. Lytras T, Theocharopoulos G, Tsiodras S, Mentis A, Panagiotopoulos T, Bonovas $\mathrm{S}$, the influenza surveillance report group. Enhanced surveillance of influenza $A(\mathrm{H} 1 \mathrm{~N} 1) \mathrm{v}$ in Greece during the containment phase. Euro Surveill. 2009;14(29):pii=19275. Available online: http://www.eurosurveillance.org/ ViewArticle.aspx?ArticleId $=19275$ 
40. European Centre for Disease Prevention and Control. ECDC Threat Assessment. First isolation of a secondary oseltamivir-resistant $A(H 1 N 1) v$ strain in Denmark. 1 July 2009. Available from: http://www.ecdc.europa.eu/en/files/ pdf/Health_topics/0907_Influenza_AH1N1v_Resistance_TA_Oseltamivir.pdf

41. European Centre for Disease Prevention and Control. ECDC Health Information. Influenza pandemics: Known facts and known unknowns. 5 May 2009. Available from: http://www.ecdc.europa.eu/en/files/pdf/Health_topics/Influenza_ pandemics_Knowns_unknowns.pdf

42. Health Protection Agency, Health Protection Scotland, National Public Health Service for Wales, HPA Northern Ireland Swine influenza investigation teams. Epidemiology of new influenza A (H1N1) virus infection, United Kingdom, April - June 2009. Euro Surveill. 2009;14(22):pii=19232. Available from: http://www. eurosurveillance.org/ViewArticle. aspx?ArticleId $=19232$

43. Health Protection Agency West Midlands H1N1v Investigation Team. Preliminary descriptive epidemiology of a large school outbreak of influenza $\mathrm{A}(\mathrm{H} 1 \mathrm{N1}) \mathrm{v}$ in the West Midlands, United Kingdom, May 2009. Euro Surveill. 2009;14(27):pii=19264. Available from: http://www.eurosurveillance.org/ ViewArticle.aspx?ArticleId $=19264$

44. Lipsitch M, Riley S, Cauchemez S,Ghani AC, Ferguson NM. Managing and Reducing Uncertainty in an Emerging Influenza Pandemic. N Engl J Med. 2009;361(2):1125.

45. Hall IM, Gani R, Hughes HE, Leach S. Real-time epidemic forecasting for pandemic influenza. Epidemiol Inf. 2007;135(3):372-85.

This article was published on 23 July 2009.

Citation style for this article: Nicoll A, Coulombier D. Europe's initial experience with pandemic (H1N1) 2009 - mitigation and delaying policies and practices . Euro Surveill. 2009;14(29):pii=19279. Available online: http://www.eurosurveillance.org/ViewArticle. aspx?ArticleId $=19279$ 